OESOPHAGUS

\title{
Endoluminal gastroplication in children with significant gastro-oesophageal reflux disease
}

\author{
M Thomson, A Fritscher-Ravens, S Hall, N Afzal, P Ashwood, C P Swain
}

Gut 2004;53:1745-1750. doi: 10.1136/gut.2004.041921

See end of article for authors' affiliations ....................

Correspondence to: DrM Thomson, Centre for Paediatric Gastroenterology, Sheffield Children's Hospital, Western Bank Sheffield S10 2TH, UK; mike.thomson@sch.nhs.uk

Revised version received 22 April 2004

Accepted for publication 27 April 2004
Aims: To describe paediatric experience, and to assess complications and therapeutic effectiveness of the use of endoluminal gastroplication in children with gastro-oesophageal reflux disease (GORD) refractory to, or dependent on, proton pump inhibitors.

Methods: Seventeen (five male) consecutive children/adolescents (median (range) age 12.4 (6.115.9) years, median (range) weight 46.0 (16.5-87.5) kg) with GORD either dependent for more than 12 months on proton pump inhibitors or non-responsive to medical treatment underwent endoscopic gastroplication using a flexible endoscopic sewing device (EndoCinch). Three plications were placed in gastric tissue below the lower oesophageal sphincter. Drug dose requirement, $\mathrm{pH}$ measurements, daily symptom severity and frequency, and validated reflux (QOLRAD) and general gastrointestinal (GSRS) quality of life scores were compared before and after endoscopic gastroplication.

Results: All patients showed post-treatment improvement in symptom severity, frequency, and quality of life scores $(p<0.0001)$. Three patients with recurrent symptomatic GORD had a repeat procedure within six weeks and did well subsequently. At up to 33 months of follow up (median 23), 14/17 patients remained off all antireflux medications, and 14/17 had maintained their symptomatic improvement. All $\mathrm{pH}$ parameters improved and had returned to normal values in 14/16 patients post-treatment and in 6/9 after one year of follow-up: in particular the reflux index had decreased from a median of $16.6 \% 10.9-$ $67 \%)$ to $2.5 \%(0.7-15.7 \%)(p<0.0001)$ six weeks and $4.3 \%(2.2-20.6)(p<0.02) 12$ months postprocedure. The only complication observed was gastric bleeding in one patient due to previously undiagnosed coagulopathy, which spontaneously resolved.

Conclusions: Endoluminal gastroplication is an effective and safe procedure in children/adolescents with significant GORD refractory to, or dependent on, medical anti-GORD therapy.
$\mathrm{R}$ egurgitation of gastric contents above the lower oesophageal sphincter is a normal physiological process in healthy infants, children, and adults. It becomes pathological and is then termed gastro-oesophageal reflux disease (GORD) when it is symptomatic and associated with sequelae. Complications include faltering growth, refractory wheezing/coughing/aspiration, acute life threatening events, apnoea, chronic otitis media, sinusitis, haematemesis, anaemia, oesophageal stricture formation, and Barrett's oesophagus. $^{12}$

Little is known of the epidemiology of gastro-oesophageal reflux in children, nevertheless gastro-oesophageal reflux is a common problem encountered in any paediatric gastroenterology clinic practice. A follow up study of 126 children with GORD in infancy showed that $55 \%$ were symptom free by 10 months and $81 \%$ by 18 months of age. ${ }^{3}$ However, those with frequent symptoms (>90 days) in the first two years of life were more likely to have symptoms by nine years of age. ${ }^{4}$ Presence of severe oesophagitis is predictive of the need for a future reconstructive procedure. ${ }^{5}$

The main aims of treatment of gastro-oesophageal reflux are to achieve relief of symptoms and prevent complications. For patients who fail to achieve control with medical therapy or are long term dependent on antireflux treatments, contemplation of a surgical antireflux procedure arises. ${ }^{1}$ The principle of any surgery in GORD is to form a reconstruction of the antireflux barrier. Nissen's fundoplication has been the treatment of choice to date but is an invasive surgical procedure associated with morbidity and mortality. ${ }^{67}$ In recent years, laparoscopic fundoplication has become popular, generally replacing the open Nissen's procedure, although superior efficacy and safety have yet to be demonstrated. ${ }^{8}$
With the laparoscopic procedure cosmesis is clearly superior, and in adult studies complications appear less common with good success rates. ${ }^{9}{ }^{10}$ More recently, an endoscopic technique termed endoluminal gastroplication (EG) has been developed, in an attempt to identify an effective and less invasive procedure. In adults this is now routinely carried out as a day case procedure and preliminary studies have shown it to be rapid, non-invasive, effective, and safe. ${ }^{11-16}$ However, medium term results are, disappointingly, not yet comparable with laparoscopic fundoplication in adults, ${ }^{8}{ }^{10-12}$ which has been studied as a preferable alternative choice to an open Nissen's fundoplication..$^{13}$ and it remains to be seen if EG is a viable alternative to laparoscopic fundoplication in adults. In this study, we have assessed the first cohort of patients in the paediatric age group undergoing endoscopic gastroplication in order to analyse its safety, potential application, and therapeutic efficacy in this age group.

\section{PATIENTS AND METHODS}

Consecutive patients presenting with GORD refractory to, or dependent for more than 12 months on, optimum medical management were offered endoscopic gastroplication after a rigorous consent procedure with parents or guardians who were all aware that this was a novel intervention in this age group. Laparoscopic Nissen's fundoplication was offered as an alternative in each case but all elected to undergo EG as the primary intervention after full discussion of the two

Abbreviations: GORD, gastro-oesophageal reflux disease; EG, endoluminal gastroplication; QOLRAD, quality of life rating score; GSRS, gastrointestinal symptom rating score; GOJ, gastro-oesophageal junction 
procedures. Hence no laparoscopic fundoplications occurred during the period encompassing this cohort of patients. Diagnosis of GORD potentially amenable to surgical treatment was made based on the following criteria:

(1) Symptoms significantly interfering with lifestyle, with or without complications of gastro-oesophageal reflux.

(2) Symptoms refractory to, or dependence for more than 12 months on, optimum medical management, including proton pump inhibitors and propulsion agents.

(3) Exclusion of allergic/eosinophilic oesophagitis (history, blood tests, oesophageal biopsies, or trial of exclusion cow's milk/soya protein from the diet).

Other markers used to assess the severity of gastrooesophageal reflux were:

(1) Presence of any of the complications of gastro-oesophageal reflux-stricture, haemorrhage, failure to thrive, significant respiratory symptoms.

(2) Abnormal GORD pH DeMeester score.

(3) Other standard parameters of $\mathrm{pH}$ severity assessment.

(4) Endoscopic scoring of oesophagitis.

(5) Abnormal quality of life (QOLRAD) $)^{15}$ and gastrointestinal symptom (GSRS) rating scores. ${ }^{16}$

Any patient with an oesophageal stricture or a hiatus hernia of greater than $2 \mathrm{~cm}$ on barium swallow or a history suggestive of oesophageal dysmotility was excluded from the study. Gastric scintiscan studies for liquid and solid phase with $t_{1 / 2}$ emptying times were assessed prior to the procedure.

As is common practice in paediatric endoscope, all procedures occurred under general anaesthesia and in the left lateral position. The procedure makes use of an EndoCinch sewing machine attached to the endoscope which in this study was used to place three pairs of stitches below the GOJ to create three internal plications of the stomach. ${ }^{14-19}$ Initially, two (for the first five procedures), and then three plications were placed, one $0.5 \mathrm{~cm}$ below the gastrooesophageal junction (GOJ) on the lesser curvature and one or two $1.5 \mathrm{~cm}$ below the GOJ on the lesser and greater curvature, which differs slightly from the reported adult studies in which various combinations of plications have been employed (for example, two circumferential, two or three longitudinal)..$^{15} 16$

Patients and parents/guardians were given a fully informed choice of an endoscopic or laparoscopic/open Nissen's fundoplication. None opted for the open surgical or laparoscopic option as firstline intervention, and consented to the endoscopic procedure on the understanding that this would not prevent progression to surgical fundoplication if necessary in the future.

A record of symptom frequency and severity score, quality of life, and gastrointestinal symptom scores (QOLRAD and GSRS), ${ }^{16}$ and daily medications (expressed as $\mathrm{mg} / \mathrm{kg} /$ day) taken was kept for six weeks prior to and subsequent to the procedure, and then at six and 12 months following the intervention. It should be pointed out that these scoring systems have been validated in adults but not in children. Nevertheless, as no similar assessment tool for GOR quality of life effects exists for the 6-16 year age group, and the questions were easily comprehensible to our patients, it was determined to be a reasonable method of semiquantifying reflux related QOL. After the procedure, a liquid diet with eight hourly ondansetron for the first 24 hours was commenced, the latter to prevent post-anaesthetic emesis. Subsequently, as is common practice following standard fundoplication, a pureed diet was advised for at least three weeks although it is not clear from existing experience with
EG whether this is strictly necessary. Any record of complications during the follow up period was kept. Any antireflux medication was gradually stopped over the subsequent week to two weeks as tolerated.

Patients were followed up at two weeks, six weeks, 12 weeks, and thereafter every 12 weeks. At six weeks and, when agreed to, at 12 months, a repeat $\mathrm{pH}$ study was carried out. In addition, at six weeks and 12 months post-procedure the following were assessed:

(1) History (clinical history, medications).

(2) Quality of life using the QOLRAD questionnaire. ${ }^{15} 16$

(3) GSRS score.

(4) Note of any complications (24 hours-1 month, 1-12 months).

(5) Weight, height, pubertal staging.

Clinical success was defined as a reduction/cessation of symptoms and medications. A reduction/cessation of duration of acid reflux and other standard $\mathrm{pH}$ parameters was determined as a technical success. Manometry of the oesophagus was declined by all but three patients in this group.

Failure of resolution of the initial symptoms or recurrence after resolution within 12 months was considered to be a failure of the procedure.

\section{Statistics}

SPSS v 10.1 was used for calculation of all statistics. Comparative data were analysed using the Wilcoxon rank sum test. Box and whisker plots with median and interquartile ranges were used for all figures.

\section{RESULTS}

Seventeen consecutive neurologically normal children and adolescents (five males, median age 12.4 (range 6.115.9) years) undergoing EG were assessed prior to and following the intervention. In 8/17, optimum medical management with proton pump inhibitor doses greater than $1.2 \mathrm{mg} / \mathrm{kg} / \mathrm{day}$ and the use of propulsion agents such as cisapride and domperidone did not control symptoms. The remaining 9/17 had symptomatic relief from, but dependency on, optimum medical management for over 12 months but they and their parents had decided that they did not wish to continue dependency on long term medications. Median weight was 46 (range 16.5-87.5) kg. No patient had a hiatus hernia on barium swallow and all had normal gastric emptying for liquid and solid phases. One patient had abnormal antroduodenal motility but nevertheless had a normal gastric scintiscan. In the three patients who had oesophageal motility and manometry studies, normal values were obtained. Endoscopy revealed modified Savary-Miller grade 0 in six and grade 1 in 11 patients, and histological grade 0 in one, grade la in six, grade $l b$ in six, and grade lc in four patients. Median follow up was 23 (range 1933) months. The first five patients had two gastroplications inserted longitudinally, $0.5 \mathrm{~cm}$ and $1.5 \mathrm{~cm}$ below the GOJ, and of these three required a second gastroplication procedure 8-12 weeks following the first due to symptomatic failure. At endoscopy it was noted that one of the plications had failed in each case. Hence, subsequently, three plications were inserted (two circumferentially $1.5 \mathrm{~cm}$ distal to the GOJ and the third $0.5 \mathrm{~cm}$ distal to the GOJ). Following this practice no repeat procedures were needed although one of these subjects subsequently underwent an unrelated surgical procedure under general anaesthesia and was not covered for post-general anaesthesia emesis with antiemetics. She had profound post-general anaesthesia vomiting and, having been completely asymptomatic, subsequently developed 

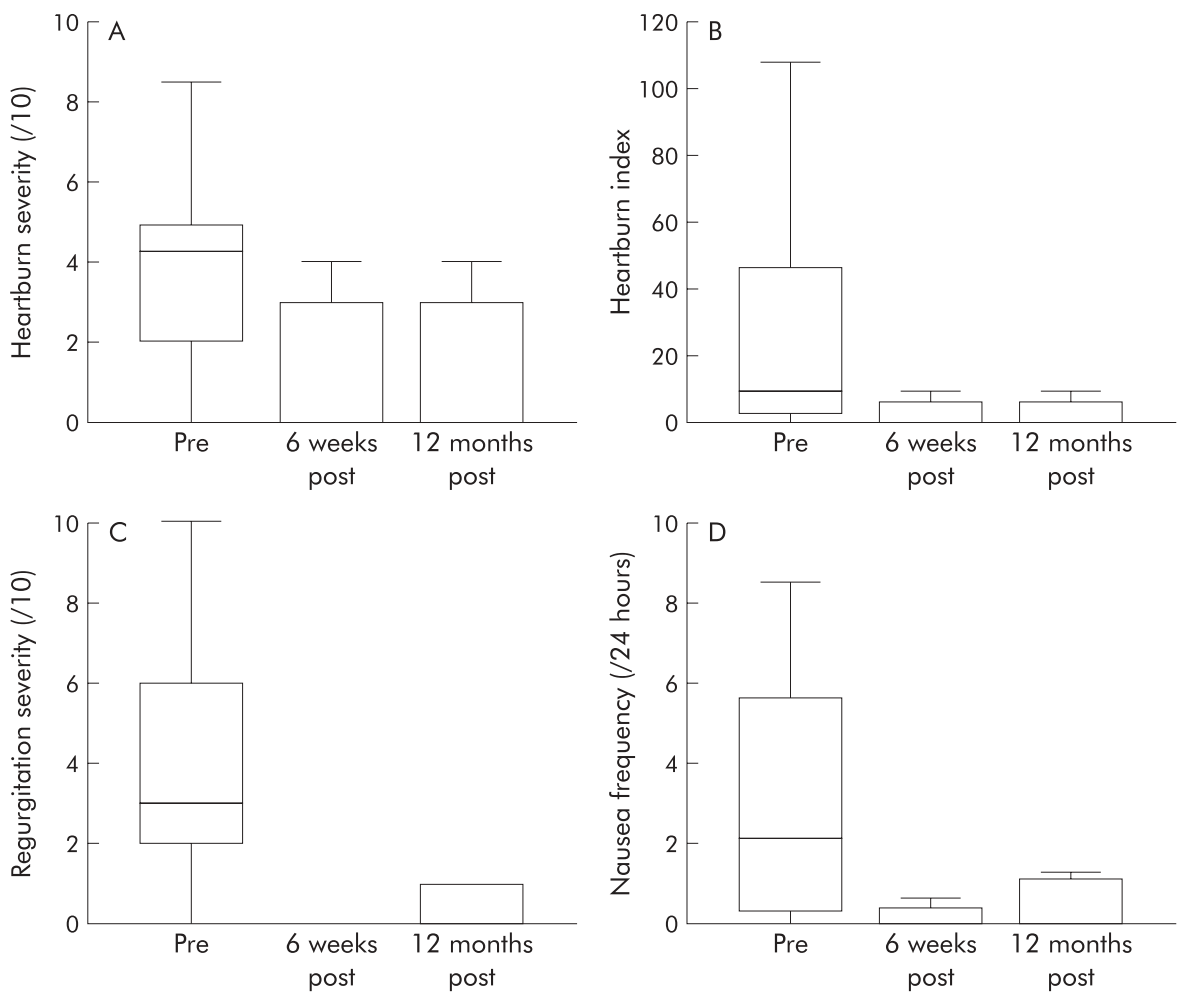

Figure 1 (A) Heartburn severity (/10) (pre $v$ six weeks post, $p=0.001$; pre $v 12$ months post, $p=0.04$ ). (B) Heartburn index (severity $\times$ frequency in 24 hours) (pre $v$ six weeks post, $p=0.001$; pre $v 12$ months post, $p=0.02$ ). (C) Regurgitation severity (/10) (pre $v$ six weeks post, $p=0.0006$; pre $v$ 12 months post, $p=0.01$ ). (D) Nausea frequency (per 24 hours) (pre $v$ six weeks post, $p=0.002$; pre $v 12$ months post, $p=0.01$ ).

GOR symptoms. Median time of the procedure was 65 (range 54-120) minutes. The procedure became quicker despite the insertion in the three repeat procedures and the next 12 procedures of three rather than two plications due to the operator learning curve

\section{Post-procedure assessments Symptom analysis}

There was significant improvement in heartburn $(p=0.001)$, regurgitation $(\mathrm{p}=0.002)$, and nausea symptom score (frequency $\times$ severity $)(p=0.013)$ at six weeks post-treatment, and this effect was sustained at 12 months post-procedure for each parameter $(\mathrm{p}<0.02, \mathrm{p}<0.002$, and $\mathrm{p}<0.002$, respectively) (fig $1 \mathrm{~A}-\mathrm{D}$ ) In addition, in those patients in whom vomiting was present there was a significant improvement in frequency/24 hours $(\mathrm{p}=0.012)$.

\section{Quality of life assessment}

Median QOLRAD and GSRS scores demonstrated a statistically significant improvement in total QOLRAD $(\mathrm{p}<0.0002)$ and GSRS $(\mathrm{p}<0.001)$, with sustained improvement after 12 months of follow up (QOLRAD $(\mathrm{p}=0.001)$ and GSRS $(\mathrm{p}=0.002)$ ) (fig $2 \mathrm{~A}, \mathrm{~B})$. Subsections of QOLRAD scores all showed improved scores at six weeks and 12 months of follow up which were statistically significant for the following parameters due to GOR: emotional distress; sleep disturbance; food and drink problems; physical/social functioning; and vitality. Total QOLRAD (maximum 175) increased from a median of 101 (range 71-149) to 165.6 (range 106.6-175) $(\mathrm{p}<0.0002)$ after six weeks of follow up and was sustained at 12 months (mean 153 (range 111-175); $\mathrm{p}=0.001$ ) (fig 2A). GSRS scores (maximum 105) increased from a median of 75 (range 48-104) to 97 (range 57-105) $(\mathrm{p}=0.0008)$ at six weeks of follow up and to 98 (range 63$105)$ at 12 months $(p=0.0008)$ (fig $2 B)$. In addition, it should be noted that pre-gastroplication scores were all on treatment and post-gastroplication scores were all off treatment except in one patient.

\section{$\mathrm{pH}$ studies}

Assessment of acid GOR before and at six weeks postprocedure by 24 hour ambulant $\mathrm{pH}$ analysis occurred in 16 patients, and in one this was not possible due to lack of patient cooperation. Nine patients had a repeat $\mathrm{pH}$ study at 12 months post-procedure. The eight who declined did so citing continued symptom control and lack of perceived personal gain from a repeat $\mathrm{pH}$ study. The following parameters were compared: reflux index; upright and supine reflux indexes; number of reflux events per hour; number of reflux events greater than five minutes in duration per 24 hour study; and DeMeester score. All pH parameters significantly improved post-treatment. Reflux index improved from a median of $16.65 \%(0.9-67.9)$ to $2.5 \%(0.7-$ 15.7) $(p=0.001)$ at six weeks and to $4.3 \%(2.2-20.6)$ $(p=0.02)$ at 12 months (fig $3 \mathrm{~A})$. Two of 16 patients at six weeks and $3 / 9$ at 12 months had a reflux index greater than $6 \%$. Upright reflux index improved from $11.9 \%(0.3-78)$ to $2.65 \%(1.5-21.3)(\mathrm{p}=0.01)$ at six weeks and was $6.8 \%(2.2-$ 29.9) (NS) at 12 months (fig 3B). The longest reflux event observed during each $\mathrm{pH}$ study decreased from 23 minutes $(2-819)$ to 5 minutes $(2-57)(\mathrm{p}=0.01)$ at six weeks, and 7 minutes $(3-37)(p=0.04)$ at 12 months. The number of reflux events per hour decreased from 8.9 (1.6-47.6) to 2.43 $(0.5-8.3)(\mathrm{p}=0.0004)$ at six weeks and to $4.74(2.3-5.8)(\mathrm{NS})$ at 12 months. The number of reflux events longer than five minutes per 24 hour study decreased from $3(0-29)$ to $0(0-$ 11) $(\mathrm{p}=0.03)$ at six weeks and to $1(0-12)(\mathrm{p}=0.08)$ at 12 months. DeMeester scores improved from $73(6.1-258)$ to $11.95(2.6-59.9)($ normal $<14.72)(p=0.002)$ at six weeks and to $19.2(11-41.4)(\mathrm{p}=0.018)$ at 12 months (fig 3C). In 

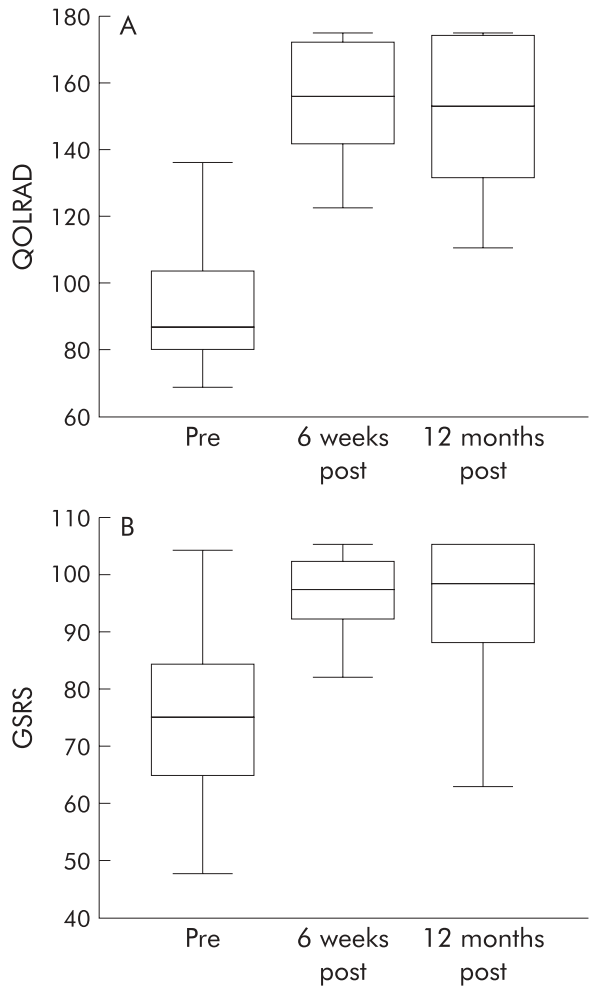

Figure 2 (a) Quality of life reflux related score (QOLRAD) (maximum, best quality, 175) (pre $v$ six weeks post, $p=0.0002$; pre $v 12$ months post, $p=0.0003$ ). (B) Gastrointestinal symptom rating score (GSRS) (maximum, best, 105) (pre $v$ six weeks post, $\mathrm{p}=0.0008$; pre $v$ 12 months post, $p=0.002$ ).

the $4 / 17$ patients in whom the reflux index was $<6 \%$, significant GOR symptoms interfering with normal lifestyle were reported, hence the decision to proceed with normal $\mathrm{pH}$ parameters. These four patients demonstrated marked improvement in quality of life and symptom scores following EG.

Routine upper endoscopic follow up was not done, and when this occurred for repeat gastroplication in the three patients who required this, histological improvement of oesophagitis was demonstrated and in each patient only one of the plications remained. One patient may require a third procedure 12 months following the initial gastroplication as her GOR symptoms returned following severe vomiting after a general anaesthetic for an unrelated issue at her local hospital, and despite knowledge of her general anaesthesia induced vomiting tendency, no prophylactic antiemetics were administered. A further patient required a third procedure at 24 months following the first procedure due to symptom re-emergence, and this has provided effective symptom control after three months of follow up.

\section{Antireflux drug requirement}

All patients except one were able to stop all of their antireflux medications within two weeks of the procedure. Prior to intervention the median dose of proton pump inhibitors (mg/ $\mathrm{kg} /$ day) (all patients) was 0.9 (range 0-2.42), domperidone (10 patients) (mg/kg/day) 0.47 (range $0.45-1.28)$ to 0 (0$0.6)$, and cisapride (five patients) $(\mathrm{mg} / \mathrm{kg} / \mathrm{day}) 0.27$ (range 0 $1.0)$ to $0(0-0.8)$. The remaining patient had suffered abnormal antroduodenal motility demonstrated on motility studies prior to the intervention but nevertheless she experienced a significant symptomatic and $\mathrm{pH}$ improvement (the latter to the normal range of the reflux index) but
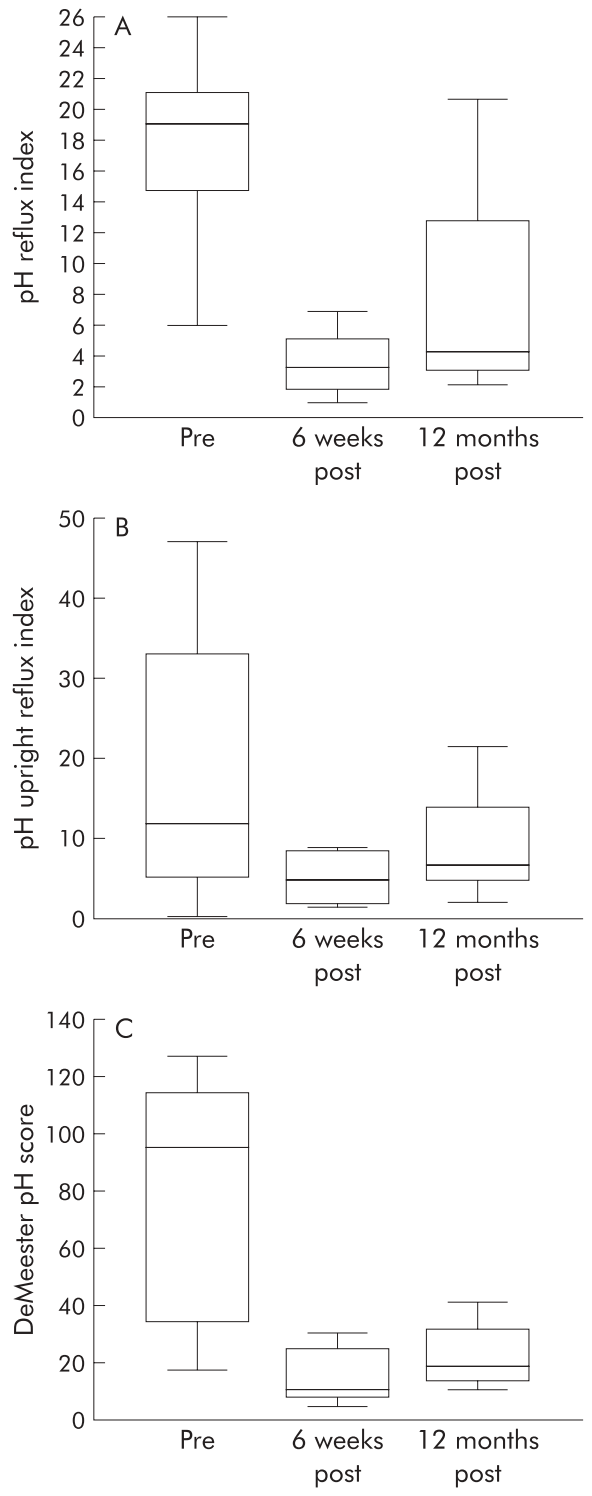

Figure 3 (A) pH reflux index (pre $v$ six weeks post, $p=0.0013$; pre $v$ 12 months post, $\mathrm{p}=0.02$ ). (B) pH upright reflux index (pre $v$ six weeks post, $p=0.01$; pre $v 12$ months post, NS). (c) DeMeester pH score (pre $v$ six weeks post, $p=0.002$; pre $v 12$ months post, $p=0.018$ ).

continued to require $1.2 \mathrm{mg} / \mathrm{kg} / \mathrm{day}$ of proton pump inhibitor and $0.9 \mathrm{mg} / \mathrm{kg} /$ day of domperidone. At 12 months of follow up, two patients remained on proton pump inhibitors at $0.2 \mathrm{mg} / \mathrm{kg}$ and $2.3 \mathrm{mg} / \mathrm{kg}$, respectively. At a median of 23 months of follow up, three patients required proton pump inhibitors and one used metoclopramide intermittently to control nausea.

\section{Complications of the procedure}

Immediately after the procedure, transient self resolving effects such as sore throat and minor epigastric abdominal pain occurred. Nausea and potential vomiting post-general anaesthesia were actively managed intravenously for 24 hours and then as required orally, and therefore were only seen in three patients. . Two patients (11.7\%) had retrosternal chest discomfort following the procedure which self resolved over the next 24 hours, and one patient had bleeding from the fundus which was noted following insertion of the plications but which did not require endoscopic intervention and stopped spontaneously. He 
required a subsequent packed red cell transfusion. With haemostatic investigation he was subsequently diagnosed with a platelet pool storage disorder and had normal coagulation studies and a full blood count prior to the procedure.

None of the adverse events associated with open or laparoscopic fundoplication occurred (for example, dysphagia, gas bloat, inability to burp).

\section{DISCUSSION}

The initial results from this cohort of children suggest that endoluminal gastroplication (EG) is safe and effective in terms of improved quality of life assessed with two validated quality of life scoring tools and objectively with improvement of all analysed $\mathrm{pH}$ parameters in 16/16 patients and return to normal values in 14/16 who underwent $\mathrm{pH}$ studies subsequent to EG. All but one patient discontinued all antireflux medications within 2-3 weeks following the procedure, a further patient returned to proton pump inhibitor use following a vomiting episode, and at nearly two years (median) of follow up, 14/17 patients remain free of proton pump inhibitor use. Lower oesophageal acid exposure, as determined by 24 hour ambulant $\mathrm{pH}$ studies, and all standard parameters of $\mathrm{pH}$ studies after the procedure returned to well within normal values in 14/16 patients. The reflux index decreased from a median of $16.5 \%$ to $4.3 \%$ at 12 months following endoscopic gastroplication, and DeMeester scores fell from a median of 73 to 19.2 (normal $<14.72$ ) at 12 months. Reflux related symptomatic relief was maintained in 15/17 patients at 12 months and, in the nine in whom it occurred, $\mathrm{pH}$ determined oesophageal acid exposure improvement was maintained in 7/9 patients at 12 months. One child had profound gastric antral hypomotility on endoluminal motility testing. However, despite this, she had an approximate halving of her symptom frequency and severity, and $\mathrm{pH}$ parameters returned to normal ranges although some residual regurgitation remained. Three children required a second procedure within six weeks of the initial endoscopic gastroplication-all had a successful result from the first gastroplication until a vomiting illness after which reflux symptoms returned very quickly. These were within the first five patients to receive the intervention in whom only two longitudinal plications were placed-when repeat endoscopy occurred in each individual no mucosal damage had occurred due to suture dehiscence and one of the plications remained in each case. Following the repeat procedure, patients were well and asymptomatic off all medical treatment although one may require a third procedure due to a further post-general anaesthesia vomiting illness when prophylactic antiemetics were not given. Subsequent to this, all other patients received three plications as described below and none has required a repeat since this arrangement was adopted despite some having suffered minor intercurrent vomiting illnesses. One patient required a third procedure two years following the first. Follow up is continuing and shows a continuing effect up to 33 months (median 23) in this cohort with sustained symptom cessation without recourse to any medical management and with a normal quality of life (except in three patients who require proton pump inhibitor use and one using intermittent metoclopramide).

Only one significant complication occurred-gastric bleeding from the gastric mucosa at the site of one suture placement-which resolved spontaneously within $30 \mathrm{~min}$ utes and did not recur. This individual required a red cell transfusion and subsequently was diagnosed with a rare platelet function disorder.

Median time for carrying out the procedure was 65 minutes for six stitches, constituting three plications, with decreasing duration as experience was gained. Most patients had an overnight stay in order to administer post-general anaesthesia antiemetics and for parental and patient reassurance. However, there is potential for this intervention to be performed on a day case basis in the future as only three patients had any nausea and antiemetics could easily be administered at home. We did not encounter any mechanical failures with the suture device preventing completion of the EG. Patients did not encounter any symptoms of dysphagia, gas bloat, or abdominal pain, as seen in children with a tight wrap due to an open or laparoscopic Nissen's fundoplication. ${ }^{8}$

The procedure makes use of an EndoCinch sewing machine attached to the endoscope, which in this study was used to place three pairs of stitches below the GOJ to create three internal plications of the stomach. ${ }^{14-16}{ }^{17-19}$ Two plications were placed circumferentially $1.5 \mathrm{~cm}$ below the GOJ and one $0.5 \mathrm{~cm}$ below the GOJ, which differs slightly from reported adult studies in which various combinations of plications have been employed (for example, two circumferential, two or three longitudinal). ${ }^{14}{ }^{15}$ Three of the first five patients who only received two plications in a longitudinal manner required repeat procedures, hence the decision to create three plications in subsequent cases.

Although intravenous sedation is commonly used in adults, a general anaesthetic is preferable for this procedure in children as for other upper endoscopic procedures. Only one patient in the main multicentre study in adults had a complication, which was a self contained suture perforation, and a number of minor short lived morbidities such as pharyngitis and abdominal and chest discomfort occurred. ${ }^{15}$ As this is a descriptive study it is clear that further possibly placebo controlled analysis of the efficacy of this technique in this age group is needed but the use of "sham" endoscopy where the patient is unaware of whether the gastroplication has actually occurred is open to ethical debate-in sham surgery the risk of harm is associated with negligible potential benefits. ${ }^{20}$

Questions have been asked regarding the way the procedure actually improves the degree of reflux and this may have relevance to the observation that we have reported better medium term results than in previous adult studies. ${ }^{12} 15$ It may be that the plications help to alter the angle of His, addressing the defective lower oesophageal sphincter ${ }^{21}$ and thereby decrease the amount of refluxate entering the oesophagus. ${ }^{11} 22$ Swain et al demonstrated an increase in the length and pressure of the lower oesophageal sphincter. ${ }^{23}$ However, other groups have not shown similar findings using oesophageal manometry. ${ }^{16}$ It may be that the angle of the GOJ is improved or that the number of transient lower oesophageal sphincter relaxations is decreased, and it is known that these are a major contributor to GORD ${ }^{24}$ and may be more important in the pathogenesis of GORD in children than in adults. Alternative explanations for the more impressive results in children may be the relatively greater depth of the plications to oesophageal wall thickness in children-three of the four children who reverted to proton pump inhibitor use were $>40 \mathrm{~kg}$ and the one who was $<40 \mathrm{~kg}$ was the individual with poor gastric emptying invoking another possible reason for failure in this smaller individual. Another reason may be the general anaesthetic applied in children which perhaps allows the operator more control and greater time to perform the procedure than in sedated adults. The last reason may be that insertion of three plications in preference to two may produce a more effective antireflux barrier than the two placed in most adult studies.

Alternative endoluminal techniques which have been promoted are endoluminal delivery of radiofrequency energy $^{25}$ and endoluminal injection of inert biopolymers ${ }^{26}$ but neither of these techniques are reversible and hence not 
desirable for application in the paediatric patient. As with any new technique, there remain concerns about the learning curve of the endoscopist. However, a previous multicentre study in adults did not show a significant difference in the learning curve of endoscopists in different centres. ${ }^{11}$

This study shows that EG is a relatively non-invasive, safe, and effective way of treating significant GORD in children and adolescents. After 12 months of prospective follow up, studies in adults have shown it to have a sustained effect. ${ }^{16}$ If similar mid-term results of EG are achieved in the paediatric population and are hence comparable with those of conventional antireflux surgery without the attendant complications, it is interesting to speculate whether this may be considered as a more cost effective and clinically preferable solution than either conventional surgery or long term medical therapy, but clearly it is too early to make such assertions in a valid way. The main difference preventing extrapolation from adult follow up studies is that obviously children are growing. Hence it remains to be seen whether this new technique will be effective long term without the need to be repeated. The advantage is that this would be a comparatively easy undertaking, compared with repeat formal fundoplications, which are usually more difficult than the original procedure due to the presence of adhesions.

The technique offers a safe alternative to laparoscopic fundoplication in those in whom this is considered necessary. It is a matter of debate whether dependency on long term medical antireflux therapy constitutes an indication for an antireflux procedure but in those children in this series who had effective symptom control with medical management (9/ 17) the parents had made an active decision that they did not want their children to remain on long term medication. The remaining 8/17 children were not responsive to optimal medical management and clearly required an antireflux procedure. Although the initial results are promising, randomised controlled trials are needed to fully assess the effectiveness of this new technique in children in comparison with the commonly used laparoscopic Nissen's fundoplication. Because this technique, and experience with it, is evolving and results are as yet based on interim results, conclusions remain tentative at present.

\section{ACKNOWLEDGEMENTS}

The authors extend their grateful thanks to the patients and parents, to the endoscopy and ward nursing staff of the Centre for Paediatric Gastroenterology at the Royal Free Hospital NHS Trust, to Mr Colin Sutton and Mr Ian Fowler of Endoscopy UK, and to Mr Andy Eakins of Bard for technical help.

\section{Authors' affiliations}

M Thomson, S Hall, N Afzal, P Ashwood, Centre for Paediatric Gastroenterology, Royal Free Hospital NHS Trust, London, UK

A Fritscher-Ravens, C P Swain, Royal London and St Bartholomew's Hospitals NHS Trust, London, UK

\section{REFERENCES}

1 Thomson M. Disorders of the oesophagus and stomach in infants. Baillieres Clin Gastroenterol 1997;11:547-71.

2 Rudolph CD, Mazur U, Liptak GS, et al. Guidelines for evaluation and treatment of gastroesophageal reflux in infants and children: recommendations of the North American Society for Pediatric Gastroenterology and Nutrition. J Pediatr Gastroenterol Nutr 2001;32(suppl 2): 1-31

3 Shepherd RW, Wren J, Evans S, et al. Gastroesophageal reflux in children. Clinical profile, course and outcome with active therapy in 126 cases. Clin Pediatr (Phila) 1987;26:55-60.

4 Martin AJ, Pratt N, Kennedy JD, et al. Natural history and familial relationships of infant spilling to 9 years of age. Pediatrics 2002;109:1061-7.

5 Hyams JS, Ricci A jr, Leichtner AM. Clinical and laboratory correlates of esophagitis in young children. J Pediatr Gastroenterol Nutr 1988;7:52-6.

6 Veit F, Schwagten K, Auldist AW, et al. Trends in the use of fundoplication in children with gastro-oesophageal reflux. J Paediatr Child Health 1995;31:121-6.

7 Festen C. Paraesophageal hernia: a major complication of Nissen's fundoplication. J Pediatr Surg 1981;16:496-9.

8 Mattioli G, Repetto P, Carlini C, et al. Laparoscopic vs open approach for the treatment of gastroesophageal reflux in children. Surg Endosc 2002;16:750-2.

9 Gotley DC, Smithers BM, Rhodes M, et al. Laparoscopic Nissen fundoplication-200 consecutive cases. Gut 1996;38:487-91.

10 Velanovich V, Ben-Menachem T, Goel S. Case-control comparison of endoscopic gastroplication with laparoscopic fundoplication in the management of gastroesophageal reflux disease. Early symptomatic outcomes. Surg Laparoscop Endosc Percut Tech 2002;12:219-23.

11 Filipi CJ, Lehman GA, Rothstein RI, et al. Transoral, flexible endoscopic suturing for treatment of GERD: a multicenter trial. Gastrointest Endosc 2001;53:416-22.

12 Mahmood Z, Byrne P, McCullough J, et al. Endocinch therapy for gastrooesophageal reflux disease: a one year prospective follow up. Gut 2002;51:1-5

13 Rothstein R, Filipi C. Endoscopic suturing for gastroesophageal reflux disease: clinical outcome with the Bard Endocinch. Gastrointest Clin N Am 2003;13:89-101.

14 Contini S, Scarpinato C. Endoscopic treatment of gastro-oesophageal reflux disease (GORD): a systematic review. Dig Liv Dis 2003;35:818-38.

15 Talley NJ, Fullerton S, Junghard O, et al. Quality of life in patients with endoscopy-negative heartburn: reliability and sensitivity of disease-specific instruments. Am J Gastroenterol 2001;96:1998-2004.

16 Wiklund IK, Junghard O, Grace E, et al. Quality of life in reflux and dyspepsia patients. Psychometric documentation of a new disease-specific questionnaire (QOLRAD). Eur J Surg Suppl 1998;583:41-9.

17 Swain CP. Endoscopic suturing. Baillieres Best Pract Res Clin Gastroenterol 1999; 13:97-108.

18 Swain CP. Endoscopic sewing and stapling machines. Endoscopy 1997:29:205-10.

19 Swain CP, Kadirkamanathan SS, Gong F, et al. Knot tying at flexible endoscopy. Gastrointest Endosc 1994;40:722-9.

20 Ridgway P, Darzi A. Placebos and standardising new surgical techniques. BMJ 2002;325:560.

21 Dent J, Holloway RH, Toouli J, et al. Mechanisms of lower oesophageal sphincter incompetence in patients with symptomatic gastrooesophageal reflux. Gut 1988;29:1020-8.

22 Kadirkamanathan SS, Yazaki E, Evans DF, et al. An ambulant porcine model of acid reflux used to evaluate endoscopic gastroplasty. Gut 1999;44:782-8.

23 Swain C, Kadairkamanarthann S, Gong F, et al. Endoscopic gastroplasty for gastro-esophageal reflux disease. Gastrointest Endosc 1997;45:AB242.

24 Thomson M, Walker-Smith J. Dyspepsia in childhood. Baillieres Clin Gastroenterol 1998;12:601-24.

25 Triadafilopoulos G, DiBaise J, Nostrant T, et al. Radiofrequency energy delivery to the gastroesophageal junction for the treatment of GERD. Gastrointest Endosc 2001;53:407-15.

26 Johnson D, Ganz R, Aisenberg J, et al. Endoscopic implantation of enteryx for treatment of GERD: 12 month results of a prospective, multicenter trial. Am J Gastroenterol 2003;98:1921-30. 